\title{
The Osteogenic Study of Tissue Engineering Bone with BMP2 and BMP7 Gene-Modified Rat Adipose-Derived Stem Cell
}

\author{
Wang Qing, Chen Guang-Xing, Guo Lin, and Yang Liu \\ Center for Joint Surgery, South West Hospital, Third Military Medical University, Chongqing 400038, China \\ Correspondence should be addressed to Yang Liu,y_Liu2012@126.com
}

Received 20 March 2012; Revised 29 April 2012; Accepted 7 May 2012

Academic Editor: Jozef Anné

Copyright () 2012 Wang Qing et al. This is an open access article distributed under the Creative Commons Attribution License, which permits unrestricted use, distribution, and reproduction in any medium, provided the original work is properly cited.

To evaluate the feasibility and advantages of constructing a novel tissue engineering bone, using $\beta$-tricalcium phosphate ( $\beta$-TCP) and rat adipose-derived stem cells (ADSCs), modified with BMP2 and BMP7 by lentivirus. In the present study, ADSCs transfected with Lv-BMP2 and Lv-BMP7, alone or together, were seeded on $\beta$-TCP scaffold and cultured in vitro. Based on the results of DNA assay, alkaline phosphatase (ALP) activity, alizarin red staining and osteogenic marker genes expression analysis, the BMP2 and BMP7 genes cotransfection group exhibited a higher degree of osteogenic differentiation in vitro. To investigate the in vivo osteogenesis of the tissue engineering bone, the ADSCs/ $\beta$-TCP constructs were implanted in rat femurs defects for 6 weeks and studied histomorphology and radiography. The results showed that BMP2 and BMP7 genes cotransfection group dramatically enhanced the efficiency of new bone formation than BMP2 group and BMP7 group in vivo. These results demonstrated that it was advantageous to construct tissue engineering bone using ADSCs cotransfected with BMP2 and BMP7 on $\beta$-TCP, providing a potential way for treating bone defects.

\section{Introduction}

The development of gene-modified tissue engineering bone has made it an attractive approach with great potential for repairing bone defects resulted from trauma, surgical resection, and congenital deformity corrections [1-3]. Many of these studies have focused on bone morphogenetic proteins (BMPs). They are multifunctional growth factors that belong to the transforming growth factor beta (TGFbeta) superfamily. BMP2 has the highest osteoinduction activity in vivo among the BMP family members [4-7]. In addition, many studies have demonstrated that local implantation of BMP7 results in the repair of critical size defects in long bones, craniofacial bones, and the formation of bony fusion masses in spinal fusions [8,9]. Laflamme's result showed that the BMP2, BMP7, and a mixture of BMP2/BMP7 all promoted osteoblast growth on the collagen scaffold, with the mixture of BMP2/BMP7 enhancing the most growth [10]. Therefore, we speculate that combined gene therapy of BMP2 and BMP7 in tissue engineering bone might have more significant effect on bone regeneration than single gene alone.
The other important aspect of tissue engineering bone is the introduction of bioactive cells into the three-dimensional porous scaffold. Stem cells hold great promise for future translational research and clinical applications in many fields. Much research has focused on mesenchymal stem cells isolated from bone marrow in vitro and in vivo however, bone marrow procurement causes considerable discomfort to the patient and yields a relatively small number of harvested cells. By contrast, adipose tissue represents an abundant and easily accessible source of adult stem cells, termed adipose-derived stem cells (ADSCs), with the ability to equally differentiate along multiple lineage pathways, such as fat, bone, cartilage, skeletal, smooth, and cardiac muscle, endothelium, hematopoietic cells, hepatocytes, and neuronal cells $[11,12]$. Animal and clinical studies have shown that ADSCs are capable of repairing damaged skeletal tissue or large-bone segmental defects $[13,14]$.

Therefore, in the present study, we further explore the osteogenic potential of tissue engineering bone using $\beta$-TCP combined with ADSCs lentivirally transfected with human BMP2 gene and human BMP7 gene, alone or together in vitro and in vivo. 
TABle 1: Primers used for real-time PCR analysis.

\begin{tabular}{|c|c|c|}
\hline Gene & Primers & Annealing temperature $\left({ }^{\circ} \mathrm{C}\right)$ \\
\hline \multirow{2}{*}{ ALP } & Forward: 5'-AGGCAGGATTGACCACGG-3' & \multirow{2}{*}{58} \\
\hline & Reverse: 5' -TGTAGTTCTGCTCATGGA-3' & \\
\hline \multirow{2}{*}{ OPN } & Forward: 5' -GACGGCCGAGGTGATAGCTT-3' & \multirow{2}{*}{63} \\
\hline & Reverse: 5'-CATGGCTGGTCTTCCCGTTGC-3' & \\
\hline \multirow{2}{*}{ OC } & Forward: 5' -AAAGCCCAGCGACTCTC-3' & \multirow{2}{*}{59} \\
\hline & Reverse: 5' -CTAAACGGTGGTGCCATAGAT-3' & \\
\hline \multirow{2}{*}{ GAPDH } & Forward: 5'-AACCCATCACCATCTTCCAGG-3' & \multirow{2}{*}{60} \\
\hline & Reverse: 5' -GCCTTCTCCATGGTGGTGAA-3' & \\
\hline
\end{tabular}

\section{Materials and Methods}

\subsection{Osteogenesis In Vitro}

2.1.1. ADSCs Culture and Infection. ADSCs were obtained from subcutaneous adipose tissue in the inguinal groove of 4-week-old Sprague-Dawley rats as previously described [15]. Briefly, the adipose tissue was washed three times with $0.1 \mathrm{~mol} / \mathrm{L}$ phosphate-buffered saline ( $\mathrm{PBS}, \mathrm{pH}=7.4$ ), and then minced finely and digested with $0.1 \%$ collagenase type I at $37^{\circ} \mathrm{C}$ for $60 \mathrm{~min}$ with vigorous shake for 15 seconds in 20 minute intervals. After centrifugation, the resulting pellet, which is defined as the adipose tissue stromal-vascular fraction (SVF), was exposed to lysis buffer for 10 minutes to remove red blood cells. The remaining cells were suspended in DMEM media supplemented with $10 \%$ FBS and $1 \%$ penicillin/streptomycin, filtered through $40 \mu \mathrm{m}$ cell strainer, and plated at $1 \times 10^{4}$ cells $/ \mathrm{cm}^{2}$ on tissue culture dishes. After reaching approximately $80 \%$ confluence, the cells were separated and cultured. ADSCs at passage 2 were transfected with human BMP2 and human BMP7, alone or together by lentivirus vector. After infection for 12 days, the medium was exchanged every 2 days. The cells at passage 3 were used for experiments.

2.1.2. Cell Seeding. BMP2/ADSCs, BMP7/ADSCs, BMP2 + BMP7/ADSCs, and ADSCs as control were collected and seeded at a density of $1 \times 10^{6}$ in $30 \mu \mathrm{L}$ on the $\beta$-TCP scaffolds and incubated at $37^{\circ} \mathrm{C}$ for $2 \mathrm{~h}$ to allow cells to attach to the scaffolds, respectively. Then the scaffolds were transferred into a 96-well plate. Each well was cultured with the normal culture medium to form tissue engineering bone. The medium was changed every 2-3 days after cell seeding on $\beta$-TCP.

2.1.3. DNA Assay. Cell proliferation of each group was determined every day by PicoGreen dsDNA reagent and Kits (Molecular Probes, OR, USA) for up to two weeks after cell seeding. A DNA standard was prepared by lysing serial dilutions of a known concentration of ADSCs. The cell scaffolds and standards were rinsed three times with PBS and incubated in $1 \mathrm{~mL}$-digestive solution (50 $\mathrm{mM} \mathrm{Na}_{3} \mathrm{PO}_{4}$, $20 \mathrm{mM}$ N-acetyl cysteine, and $28 \mathrm{mg} / \mathrm{mL}$ papain). The specimens were vortexed for $10 \mathrm{~min}$, then $10 \mathrm{~mL}$ supernatant was mixed with $10 \mathrm{~mL}$ PicoGreen dsDNA quantitation reagent in darkroom for $5 \mathrm{~min}$, and the DNA content was quantified using a fluorospectrometer.

2.1.4. Alkaline Phosphatase Enzyme Activity (ALP). Each group construct was analyzed at 14 days after cell seeding as previously described [16]. The scaffolds were homogenized with $1 \mathrm{~mL}$ Tris buffer ( $\mathrm{pH}$ 7.4, Sigma, USA), and sonicated. The cell lysate $(0.1 \mathrm{~mL})$ was mixed with $0.5 \mathrm{~mL}$ p nitrophenol phosphate substrate solution (Sigma, USA) and $0.5 \mathrm{~mL}$ alkaline phosphatase buffer solution (Sigma, USA). After incubation at $37^{\circ} \mathrm{C}$ for $15 \mathrm{~min}, 10 \mathrm{~mL}$ of $0.05 \mathrm{~N} \mathrm{NaOH}$ were added to stop the reaction. The production of $\mathrm{p}$ nitrophenol in the presence of ALP was measured by monitoring light absorbance of the solution at $405 \mathrm{~nm}$ at $1 \mathrm{~min}$ increments. The slope of the absorbance versus time plot was used to calculate the ALP activity.

2.1.5. Alizarin Red S Staining. Alizarin red S staining was used to evaluate ADSCs mineralization on $\beta$-TCP scaffolds. At 14 days after cell seeding, the constructs were fixed in $4 \%$ paraformaldehyde at $4^{\circ} \mathrm{C}$ for $24 \mathrm{~h}$, and frozen at $-20^{\circ} \mathrm{C}$, then sectioned at $10 \mu \mathrm{m}$ in thickness. After being washed with $0.01 \mathrm{M}$ PBS, sections were stained with the Alizarin Red Solution (2\%, pH 4.2) for $10 \mathrm{~min}$, followed by extensive washing with distilled water to remove the remaining stain.

2.1.6. Real-Time Quantitative PCR Analysis ( $q P C R$ ). At 14 days, total RNA was extracted from each group by the TRIzol method strictly following the manufacturer's protocol (Invitrogen, USA). The first-strand cDNA was synthesized from $1 \mu \mathrm{g}$ RNA with virus reverse transcriptase (TaKaRa, Japan), and used for quantitative real-time PCR. Expression levels of representative genes, including ALP, osteopontin $(\mathrm{OPN})$, and osteocalcin (OC), were quantified with an $\mathrm{ABI}$ 7300 real-time PCR system (Applied Biosystems, USA) and SYBR green PCR reaction mix (TaKaRa, Japan). Primers and annealing temperature for each gene are listed in Table 1. The program used was $95^{\circ} \mathrm{C}$ for 5 minutes, 40 cycles of $95^{\circ} \mathrm{C}$ for 15 seconds, annealing temperature for 1 minute, and $72^{\circ} \mathrm{C}$ for $30 \mathrm{~s}$. Melting analysis and agarose gel electrophoresis were performed to confirm the specificity of the PCR products. The relative expression levels of genes were analyzed using the $2^{-\Delta \Delta \mathrm{Ct}}$ method by normalizing with GAPDH housekeeping gene expression, and presented as fold increase relative to the control group. 


\subsection{Osteogenesis In Vivo}

2.2.1. Preparation of Bone Defect Model and Implantation. Forty healthy Sprague-Dawley rats weighting about $250 \mathrm{~g}$ each were divided into four groups for the implantations of ADSCs/ $\beta$-TCP, BMP2/ADSCs/ $\beta$-TCP, BMP7/ADSCs/ $\beta$-TCP, and BMP2 + BMP7/ADSCs/ $\beta$-TCP. Rats were anesthetized with celiac injections of $10 \%$ chloral hydrate $(3 \mathrm{~mL} / \mathrm{kg}$ body weight), and approximately $2 \mathrm{~mm}$ diameter defect was created on the medial femur by an electric drill. The cell-scaffold constructs were placed into the defects via a press fit.

2.2.2. Radiography and Histological Detection. Radiographs and histomorphology of rat femurs were examined at 2, 4 , and 6 weeks after the surgery. At each time point, rats were anesthetized and carried out X-ray radiography. Images were obtained by SPECT/CT (Philips, the Netherlands). After radiography examination, rats were sacrificed, and the scaffolds together with surrounding tissue were excised, stained with hematoxylin and eosin $(\mathrm{H} \& \mathrm{E})$, and observed the healing condition of the defect by light microscope (Olympus, Japan).

2.3. Statistical Analysis. All data are expressed as means \pm SD. SPSS 11.0 statistical software was used for repeated measurement variance analysis and ordinary ANOVA. Differences at $P<0.05$ were considered statistically significant.

\section{Results}

\subsection{Osteogenesis In Vitro}

3.1.1. DNA Assay. The cell proliferation of BMP2/ADSCs, BMP7/ADSCs, and BMP2 + BMP7/ADSCs attached onto $\beta$-TCP scaffolds was determined by the PicoGreen dsDNA assay for 14 days, and the results were shown in Figure 1. The corresponding DNA quantity of each group showed a similar trend, and no significant difference could be found $(P>$ $0.05)$. DNA quantity increased with time gradually during the first week of culture, peaked at day 7 and then leveled off, following a plateau phase. However, DNA quantity of viable cells still exhibited an increase of around 3-fold at day 14 compared to the initial quantity.

3.1.2. Alkaline Phosphatase Enzyme (ALP) Activity. The ALP activity of each group was assessed at 14 days after cell seeding. As shown in Figure 2, the ALP activity was enhanced respectively 4.9-fold and 5.3-fold in BMP2/ADSCs group and BMP7/ADSCs group compared to that in control group $(P<$ 0.05). In BMP2 + BMP7/ADSCs group, the ALP activity was approximately 8 -fold greater compared to the control group $(P<0.05)$.

3.1.3. Alizarin Red S Staining. As shown in Figure 3, after cell seeding at 14 days, more obvious positive staining of Alizarin red S in BMP2 + BMP7/ADSCs group (Figure 3(d)) was observed than that in BMP2/ADSCs and BMP7/ADSCs groups (Figures $3(\mathrm{~b})$ and $3(\mathrm{c})$ ). The result indicated that

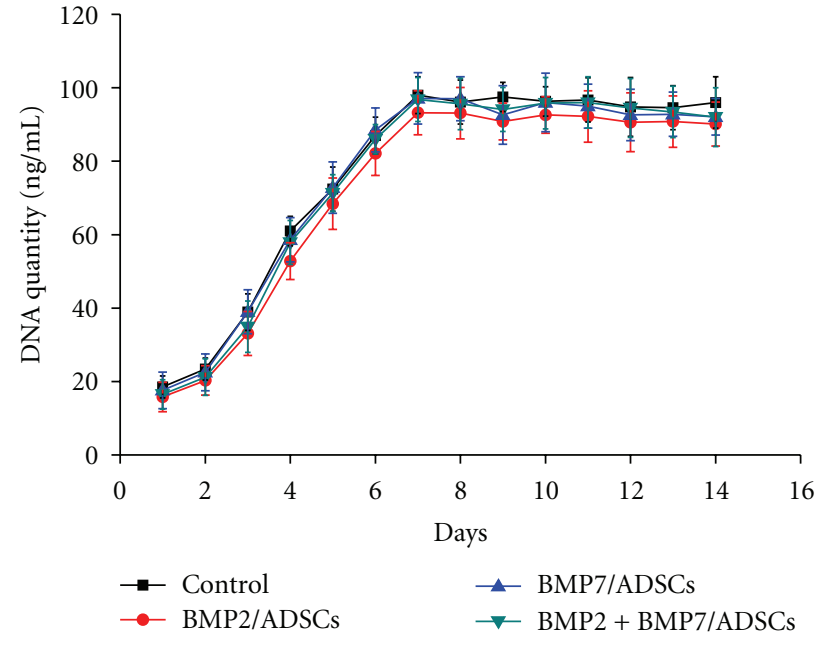

FIGURE 1: The proliferation curves of control group, BMP2/ADSCs group, BMP7/ADSCs group, and BMP2 + BMP7/ADSCs group on the $\beta$-TCP scaffolds for two weeks after cell seeding. Results are shown as mean $\pm \mathrm{SD}$ ( $n=3$ for each group).

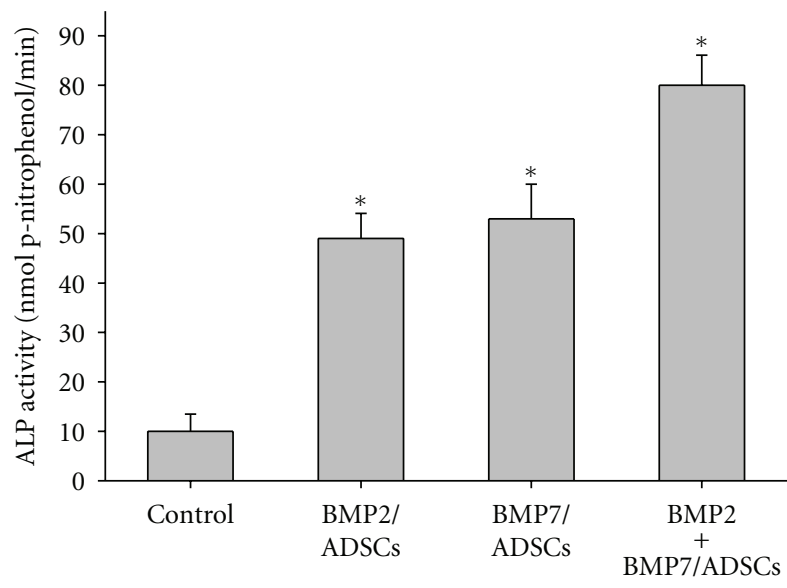

FIgURE 2: Detection of ALP activities for control, BMP2/ADSCs, BMP7/ADSCs, and BMP2 + BMP7/ADSCs groups at 14 day after cell seeding. Results are shown as mean $\pm \mathrm{SD}(n=3$ for each group, $\left.{ }^{*} P<0.05\right)$.

ADSCs modified with both genes make much more mineralization than that modified with single gene.

3.1.4. Real-Time Quantitative PCR Analysis. Figure 4 shows the relative expression of ADSCs on $\beta$-TCP scaffolds for osteogenic gene. At day 14 after cell seeding, the mRNArelative expression of osteogenic marker genes ALP, OPN, and OC in BMP2 + BMP7/ADSCs group was higher compared to BMP2/ADSCs group and BMP7/ADSCs group, and respectively, 9.5 times, 5.2 times, and 3.8 times more than those of control group $(P<0.05)$. 


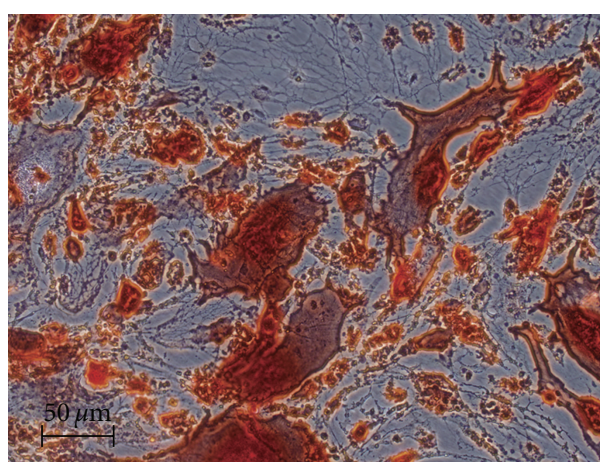

(a)

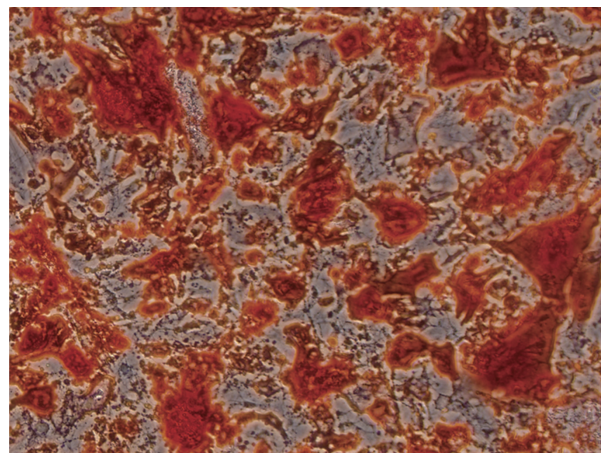

(c)

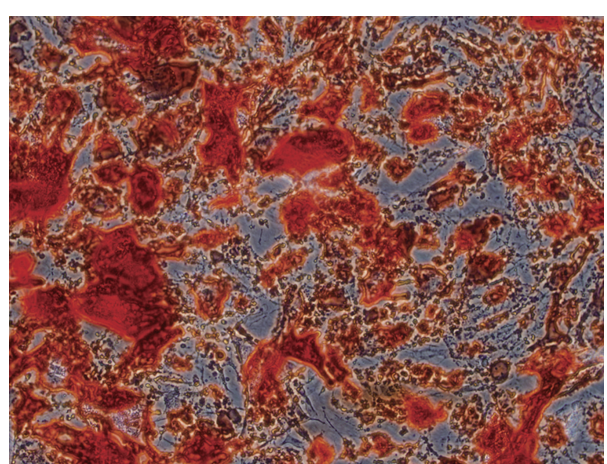

(b)

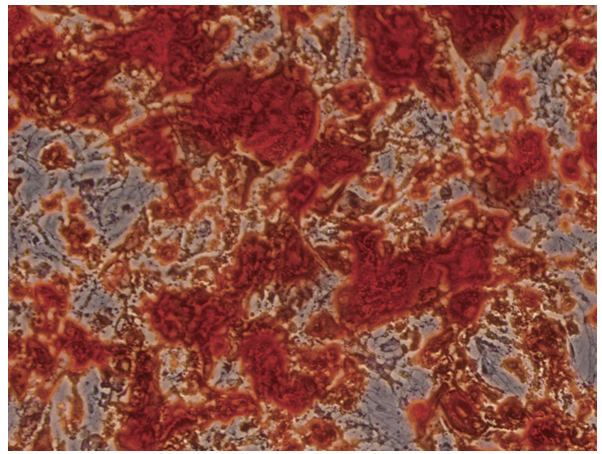

(d)

FIGURE 3: Alizarin red S staining for (a) control group, (b) BMP2/ADSCs group, (c) BMP7/ADSCs group, and (d) BMP2 + BMP7/ADSCs group at 14 days after cell seeding. Bar $=50 \mu \mathrm{m}$.

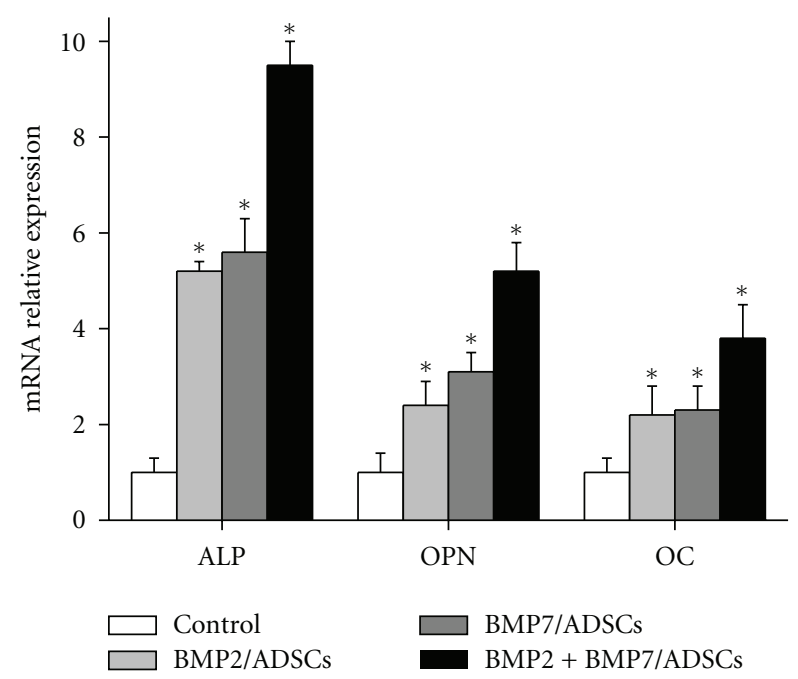

FIGURE 4: The mRNA-relative expression analysis of osteogenic marker genes ALP, OPN, and OC in control, BMP2/ADSCs, BMP7/ADSCs, and BMP2 + BMP7/ADSCs groups. Results are shown as mean $\pm \mathrm{SD}\left(n=3\right.$ for each group, $\left.{ }^{*} P<0.05\right)$.

\subsection{Osteogenesis In Vivo}

3.2.1. Behavior of Animal Model after Surgery. A $2 \mathrm{~mm}-$ diameter defect was created on the femur middle. The constructs of cell and scaffold were placed into the defects. The dietary and behavior reduced at the first day after surgery, but the behavior returned to normal at the second day. No obvious infection phenomena was observed in all groups.

3.2.2. Radiography. Figure 5 shows the radiographical images of the femur defects after surgery. At 2 weeks, there was no markedly newly formed bone tissue in each group. At 4 weeks, there was partly newly formed high-density tissue in the defects of all groups, and the amount of the new tissue was more in the BMP2 + BMP7/ADSCs constructs treated femurs than those treated with either the BMP2/ADSCs or BMP7/ADSCs. At 6 weeks, there was incremental high-density tissue in BMP2/ADSCs and BMP7/ADSCs constructs treated femurs. But the bone defects were not healed completely. In BMP2 + BMP7/ADSCs group, the femur defect has been basically healed.

3.2.3. Histological Observation. As shown in Figure 6, at week 2 after surgery, connective tissues filled the defects in all groups. Scaffold's pores were filled by inflammatory cells. At week 4 after surgery, new bone formation was observed in all implanted defects. In BMP2/ADSCs and BMP7/ADSCs group, a small amount of the inflammatory cells can still be seen inside the scaffolds. In BMP2 + BMP7/ADSCs group, the scaffold had been replaced with neogenetic tissue, including a large number of new trabecular bone and fibrous tissue. At week 6 after surgery, the inflammatory 

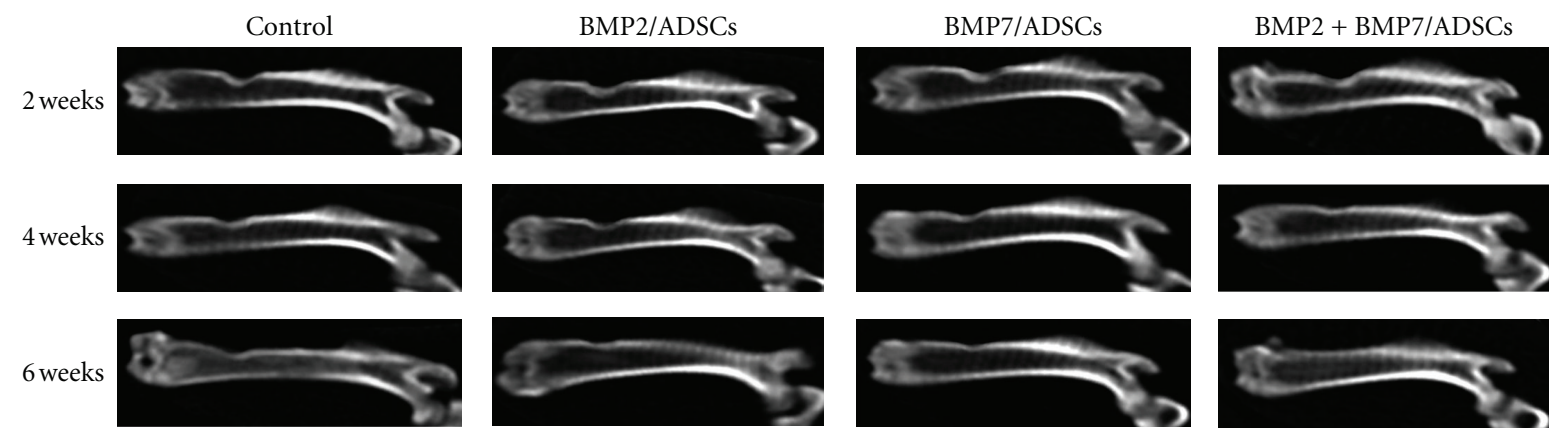

FIGURE 5: X-rays photograph of rat femurs defects in control, BMP2/ADSCs, BMP7/ADSCs, and BMP2 + BMP7/ADSCs groups at 2 weeks, 4 weeks, and 6 weeks after surgery.

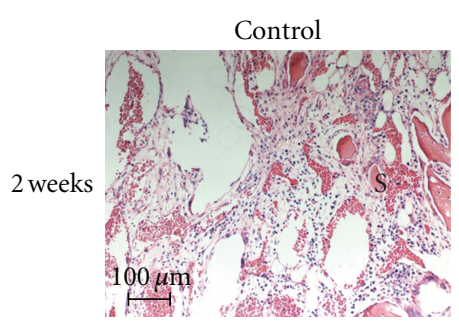

(a)

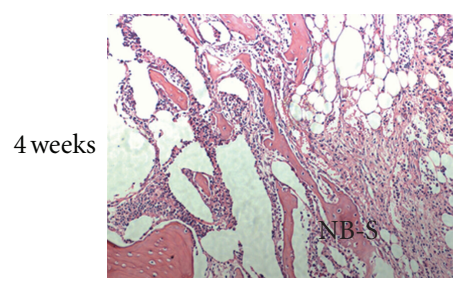

(e)

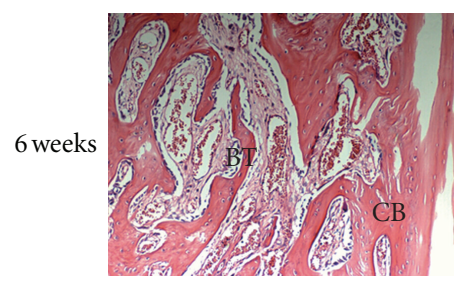

(i)

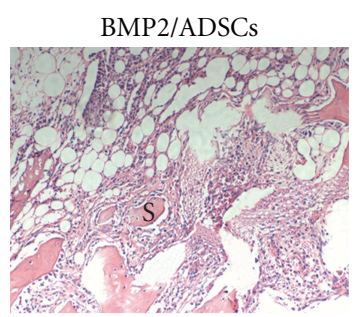

(b)

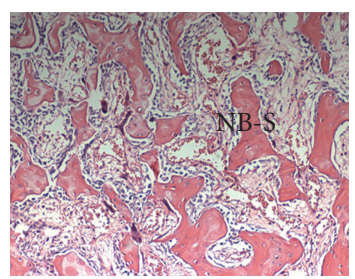

(f)

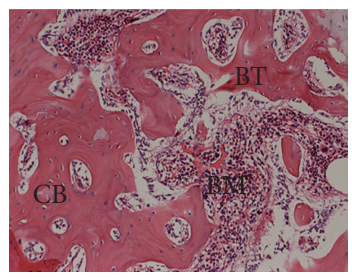

(j)

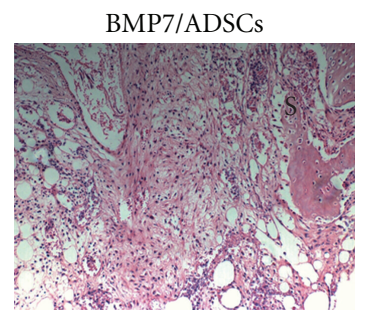

(c)

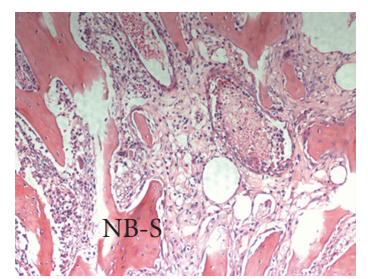

(g)

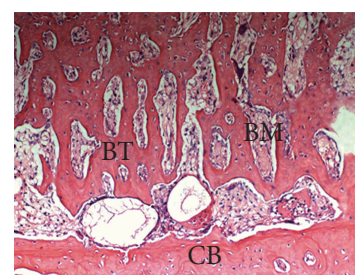

(k)

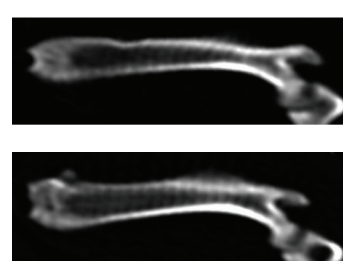


Bone tissue engineering methods consist of three elements: a donor cell source, a three-dimensional scaffold, or matrix and osteoinductive growth factors [23]. Therefore, a suitable scaffold for bone tissue engineering is also critical for the success of gene therapy strategy. $\beta$-TCP shows excellent osteoconductivity and biocompatibility, and its biodegradation rate could be easily controlled. The novel porous $\beta$-TCP scaffolds applied in this study has been proved to have prominent osteoconductive activity and exhibited good osteogenic activity both in vitro and in vivo with the aid of osteogenic medium in a previous study [24, 25]. In our study, the dsDNA assay confirmed that ADSCs can easily adhere to, and proliferate inside the $\beta$-TCP scaffolds. The ALP activity assay, Alizarin red S staining, and real-time PCR analysis results also indicated that the novel porous $\beta$-TCP scaffolds can support the proliferation and osteogenic differentiation of rat ADSCs in vitro.

ADSCs modified with BMP2 and BMP7 have emerged as an effective strategy for bone regeneration [26, 27]. Koh et al. evaluated the ability of BMP2 homodimer, BMP7 homodimer, or BMP2/7 heterodimers to stimulate SMAD, p38, ERK, and JNK pathways in C2C12 cells and have demonstrated that BMP2/7 heterodimers have enhanced ability to stimulate alkaline phosphatase and Smad 1,5,8 phosphorylation relative to equivalent amounts of BMP2 or BMP7 homodimers [28]. Zhu et al., confirmed that combination of BMP2 and BMP7 gene transfer led to a significant increase in osteoblastic differentiation compared with single BMP gene transfer in both C2C12 and MC3T3-E1 cells [29]. These investigations indicate that the mixture of BMP2 and BMP7 can induce bone formation significantly more effective and are consistent with our results.

Heterodimeric BMPs can increase biological activity [30] and facilitate more rapid bone regeneration in better quality [31]. In the present study, in vitro results indicated that ADSCs co-expressing BMP2 and BMP7 on $\beta$-TCP scaffolds exhibited a higher degree of osteogenic differentiation compared to those expressing individually BMP2 and BMP7. The results of in vitro experiments prompted us to investigate the osteogenesis of the constructs in vivo. In order to obtain defect repairing in a short period of time, we adopted a cavity defect model in a rat femur and investigated the tissue response to the cell-scaffold transplant. Radiographic and histological studies were performed on the specimens after different implantation periods. Active bone regeneration in the defects was found in all ADSCs/ $\beta$-TCP constructs. However, the ADSCs modified with BMP2 and BMP7 constructs presented faster and more effective osteogenesis at the defect area than other groups in various implantation periods. Therefore, it was a promising approach using ADSCs cotransfected with BMP2 and BMP7 seeded on $\beta$ TCP to construct tissue engineering bone for repairing bone defects.

\section{Conclusion}

In the present study, the in vitro experimental results indicated that ADSCs cotransfected with human BMP2 and
BMP7 grown on $\beta$-TCP exhibited good attachment and growth, and a higher degree of osteogenic differentiation than single gene group. The in vivo experiment demonstrated that the BMP2 + BMP7/ADSCs group implanting present faster and more effective osteogenesis than BMP2/ADSCs group or BMP7/ADSCs group. The results demonstrated that it was advantageous to construct tissue engineering bone using $\beta$-TCP combined with ADSCs co-transfected with $\mathrm{BMP} 2$ and BMP7, providing a new idea for treating bone defects.

\section{References}

[1] J. C. Roldán, R. Detsch, S. Schaefer et al., "Bone formation and degradation of a highly porous biphasic calcium phosphate ceramic in presence of BMP-7, VEGF and mesenchymal stem cells in an ectopic mouse model," Journal of CranioMaxillofacial Surgery, vol. 38, no. 6, pp. 423-430, 2010.

[2] X. Q. Jiang, J. G. Chen, S. Gittens, C. J. Chen, X. L. Zhang, and Z. Y. Zhang, "The ectopic study of tissue-engineered bone with hBMP-4 gene modified bone marrow stromal cells in rabbits," Chinese Medical Journal, vol. 118, no. 4, pp. 281-288, 2005.

[3] R. M. Schek, E. N. Wilke, S. J. Hollister, and P. H. Krebsbach, "Combined use of designed scaffolds and adenoviral gene therapy for skeletal tissue engineering," Biomaterials, vol. 27, no. 7, pp. 1160-1166, 2006.

[4] O. Jeon, S. J. Song, H. S. Yang et al., "Long-term delivery enhances in vivo osteogenic efficacy of bone morphogenetic protein-2 compared to short-term delivery," Biochemical and Biophysical Research Communications, vol. 369, no. 2, pp. 774$780,2008$.

[5] X. L. Xu, J. Lou, T. Tang et al., "Evaluation of different scaffolds for BMP-2 genetic orthopedic tissue engineering," Journal of Biomedical Materials Research—Part B, vol. 75, no. 2, pp. 289303, 2005.

[6] K. R. Dai, X. L. Xu, T. T. Tang et al., "Repairing of goat tibial bone defects with BMP-2 gene-modified tissue-engineered bone," Calcified Tissue International, vol. 77, no. 1, pp. 55-61, 2005.

[7] Y. Kiyozuka, H. Miyazaki, K. Yoshizawa et al., "An autopsy case of malignant mesothelioma with osseous and cartilaginous differentiation: bone morphogenetic protein-2 in mesothelial cells and its tumor," Digestive Diseases and Sciences, vol. 44, no. 8, pp. 1626-1631, 1999.

[8] M. R. Bong, E. L. Capla, K. A. Egol et al., "Osteogenic protein1 (bone morphogenic protein-7) combined with various adjuncts in the treatment of humeral diaphyseal nonunions," Bulletin, vol. 63, no. 1-2, pp. 20-23, 2005.

[9] R. Bilic, P. Simic, M. Jelic et al., "Osteogenic protein-1 (BMP7) accelerates healing of scaphoid non-union with proximal pole sclerosis," International Orthopaedics, vol. 30, no. 2, pp. 128-134, 2006.

[10] C. Laflamme and M. Rouabhia, "Effect of BMP-2 and BMP7 homodimers and a mixture of BMP-2/BMP-7 homodimers on osteoblast adhesion and growth following culture on a collagen scaffold," Biomedical Materials, vol. 3, no. 1, Article ID 015008, 2008.

[11] M. L. Tong, M. Martina, D. W. Hutmacher, J. H. P. O. Hui, H. L. Eng, and B. Lim, "Identification of common pathways mediating differentiation of bone marrow- and adipose tissuederived human mesenchymal stem cells into three mesenchymal lineages," Stem Cells, vol. 25, no. 3, pp. 750-760, 2007. 
[12] J. K. Fraser, I. Wulur, Z. Alfonso, and M. H. Hedrick, "Fat tissue: an underappreciated source of stem cells for biotechnology," Trends in Biotechnology, vol. 24, no. 4, pp. 150-154, 2006.

[13] X. Li, J. Yao, L. Wu et al., "Osteogenic induction of adiposederived stromal cells: not a requirement for bone formation in vivo," Artificial Organs, vol. 34, no. 1, pp. 46-54, 2010.

[14] J. Li, Q. Zhao, E. Wang, C. Zhang, G. Wang, and Q. Yuan, "Transplantation of Cbfa1-overexpressing adipose stem cells together with vascularized periosteal flaps repair segmental bone defects," Journal of Surgical Research. In press.

[15] G. Lin, M. Garcia, H. Ning et al., "Defining stem and progenitor cells within adipose tissue," Stem Cells and Development, vol. 17, no. 6, pp. 1053-1063, 2008.

[16] J. Jiang, C. Y. Fan, and B. F. Zeng, "Experimental construction of BMP2 and VEGF gene modified tissue engineering bone in vitro," International Journal of Molecular Sciences, vol. 12, no. 3, pp. 1744-1755, 2011.

[17] X.-Z. Sun, G.-H. Liu, Z.-Q. Wang et al., "Over-expression of $\mathrm{VEGF}_{165}$ in the adipose tissue-derived stem cells via the lentiviral vector," Chinese Medical Journal, vol. 124, no. 19, pp. 3093-3097, 2011.

[18] W. G. Wang, S. Q. Lou, X. D. Ju, K. Xia, and J. H. Xia, “in vitro chondrogenesis of human bone marrow-derived mesenchymal progenitor cells in monolayer culture: activation by transfection with TGF- $\beta 2$," Tissue and Cell, vol. 35, no. 1, pp. 69-77, 2003.

[19] O. Sugiyama, D. Sung An, S. P. K. Kung et al., "Lentivirusmediated gene transfer induces long-term transgene expression of BMP-2 in vitro and new bone formation in vivo," Molecular Therapy, vol. 11, no. 3, pp. 390-398, 2005.

[20] W. K. Hsu, O. Sugiyama, S. H. Park et al., "Lentiviral-mediated BMP-2 gene transfer enhances healing of segmental femoral defects in rats," Bone, vol. 40, no. 4, pp. 931-938, 2007.

[21] J. M. Mcmahon, S. Conroy, M. Lyons et al., "Gene transfer into rat mesenchymal stem cells: a comparative study of viral and nonviral vectors," Stem Cells and Development, vol. 15, no. 1, pp. 87-96, 2006.

[22] L. Naldini, U. Blomer, F. H. Gage, D. Trono, and I. M. Verma, "Efficient transfer, integration, and sustained long-term expression of the transgene in adult rat brains injected with a lentiviral vector," Proceedings of the National Academy of Sciences of the United States of America, vol. 93, no. 21, pp. 11382-11388, 1996.

[23] F. R. A. J. Rose and R. O. C. Oreffo, "Bone tissue engineering: hope vs hype," Biochemical and Biophysical Research Communications, vol. 292, no. 1, pp. 1-7, 2002.

[24] G. Liu, L. Zhao, L. Cui, W. Liu, and Y. Cao, “Tissue-engineered bone formation using human bone marrow stromal cells and novel $\beta$-tricalcium phosphate," Biomedical Materials, vol. 2, no. 2, article 04, pp. 78-86, 2007.

[25] V. Vindigni, R. Cortivo, L. Iacobellis, G. Abatangelo, and B. Zavan, "Hyaluronan benzyl ester as a scaffold for tissue engineering," International Journal of Molecular Sciences, vol. 10, no. 7, pp. 2972-2985, 2009.

[26] Y. Ren, C. Han, Y. Jia, H. Yin, and S. Li, "Expression of human bone morphogenetic protein 7 gene in adipose-derived stem cells and its effects on osteogenic phenotype," Zhongguo Xiu Fu Chong Jian Wai Ke Za Zhi, vol. 25, no. 7, pp. 848-853, 2011.

[27] O. Jeon, J. W. Rhie, I. K. Kwon, J. H. Kim, B. S. Kim, and S. H. Lee, "In vivo bone formation following transplantation of human adipose-derived stromal cells that are not differentiated osteogenically," Tissue Engineering-Part A, vol. 14, no. 8, pp. 1285-1294, 2008.
[28] J. T. Koh, Z. Zhao, Z. Wang, I. S. Lewis, P. H. Krebsbach, and R. T. Franceschi, "Combinatorial gene therapy with BMP2/7 enhances cranial bone regeneration," Journal of Dental Research, vol. 87, no. 9, pp. 845-849, 2008.

[29] W. Zhu, B. A. Rawlins, O. Boachie-Adjei et al., "Combined bone morphogenetic protein-2 and -7 gene transfer enhances osteoblastic differentiation and spine fusion in a rodent model," Journal of Bone and Mineral Research, vol. 19, no. 12, pp. 2021-2032, 2004.

[30] A. Aono, M. Hazama, K. Notoya et al., "Potent ectopic boneinducing activity of bone morphogenetic protein- 4-7 heterodimer," Biochemical and Biophysical Research Communications, vol. 210, no. 3, pp. 670-677, 1995.

[31] J. Wang, Y. Zheng, J. Zhao et al., "Low-dose rhBMP2/7 heterodimer to reconstruct peri-implant bone defects: a micro-CT evaluation," Journal of Clinical Periodontology, vol. 39, no. 1, pp. 98-105, 2012. 


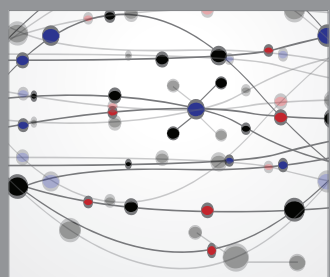

The Scientific World Journal
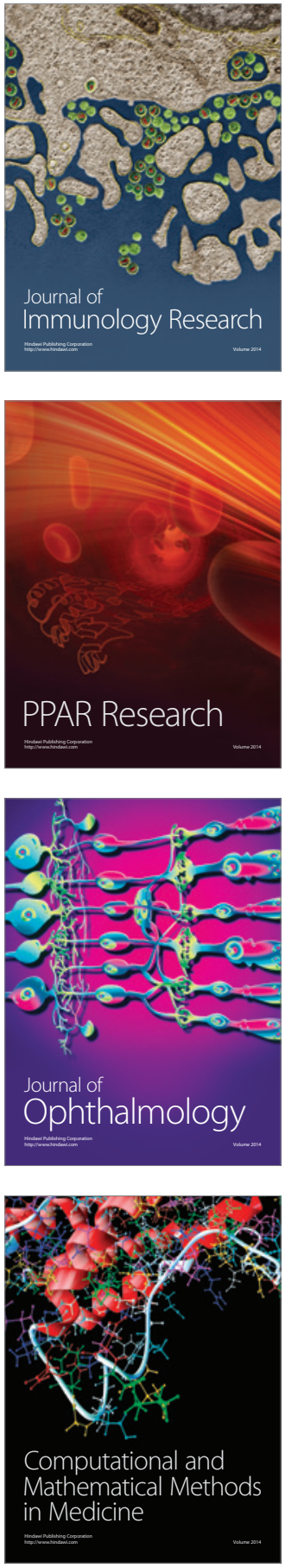

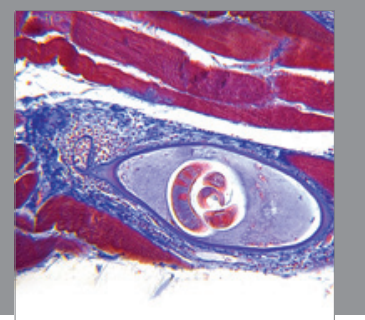

Gastroenterology

Research and Practice
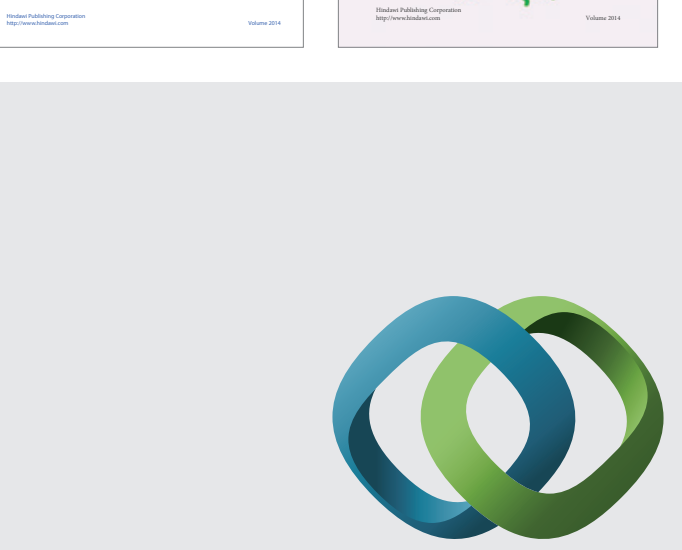

\section{Hindawi}

Submit your manuscripts at

http://www.hindawi.com
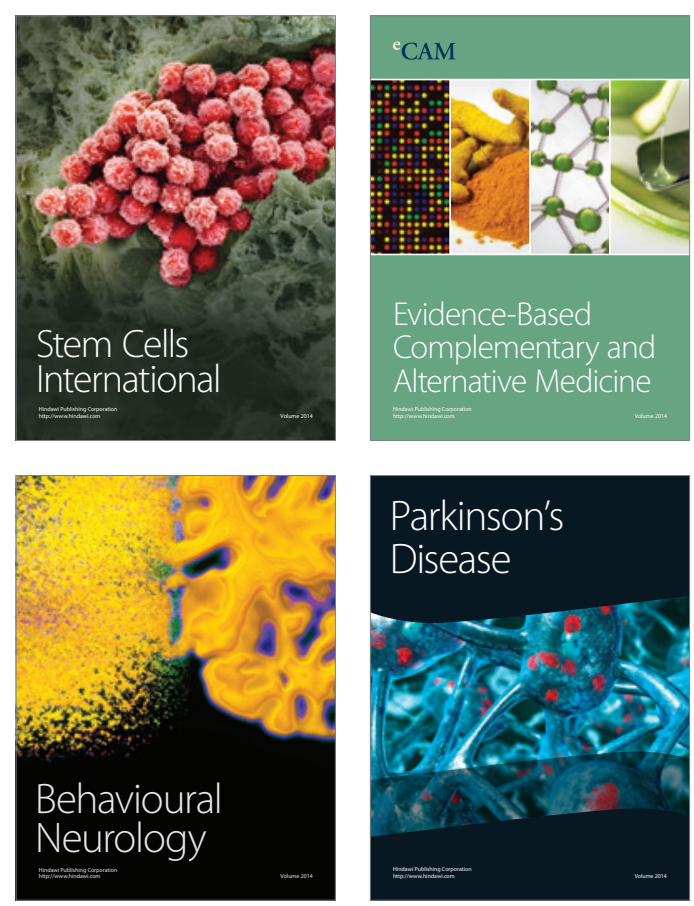

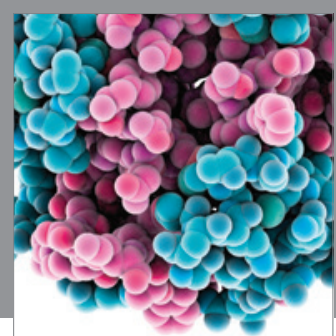

Journal of
Diabetes Research

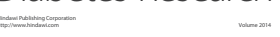

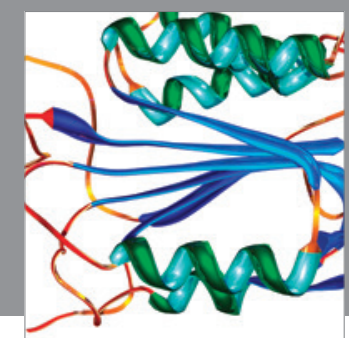

Disease Markers
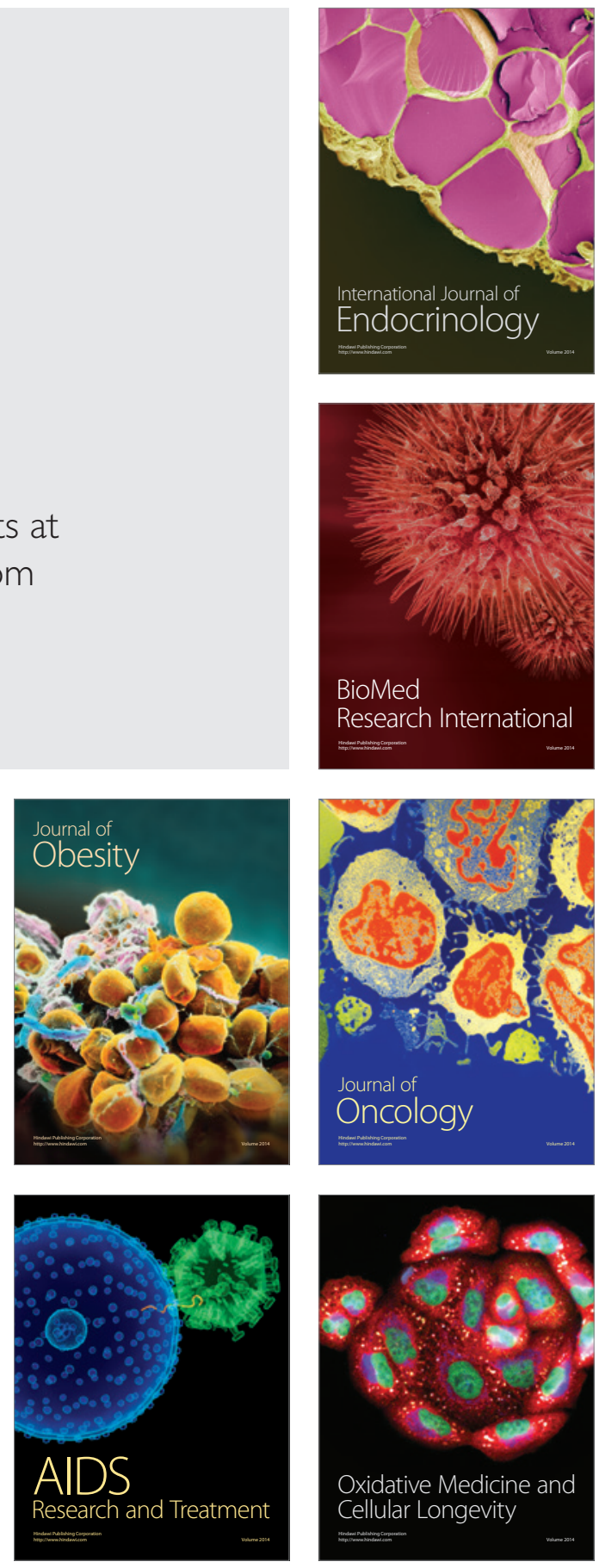